\title{
Cyclic heating effect on hardness of steel
}

\author{
[Tahany W. Sadak]
}

\begin{abstract}
Presented work discusses research results concerning the effect of the heat treatment process. Thermal fatigue which expresses repeated heating and cooling processes affect the ductility or the brittleness of the material. In this research 70 specimens of steel $(1.5 \mathrm{~mm}$ thickness, $85 \mathrm{~mm}$ length, $32 \mathrm{~mm}$ width) are subjected to thermal fatigue at different conditions. Heating temperatures; $T_{h}=100,300$ and $500{ }^{\circ} \mathrm{C}$. Number of repeated cycles; $N=1$ to 100 . Results are evaluated then compared to each other and to that of specimens without subjected to thermal fatigue.
\end{abstract}

Keywords - steel alloys, thermal analysis, heat treatment, hardness, thermal fatigue .

\section{Introduction}

Thermal fatigue specifies the process of repeated heating and cooling of machine parts. Some investigators show the effect of cyclic heat treatment on phase composition and structure of titanium alloys [1,2] others show the effect of repeated heating on tempering or hardening of steels $[3,4,5]$. Heat treatment is also used to increase the strength of materials by altering some certain manufacturability objectives especially after the materials might have undergo major stresses like forging and welding [6].

The mechanical properties such as ductility, toughness, strength, hardness and tensile strength can easily bemodified by heat treating the medium carbon steel to suit a particular design purpose. Tensile specimens were produced from medium carbon steel and were subjected to various forms of heat treatment processes like annealing, normalizing, hardening and tempering [7]. Different machine tools and elements are subjected to thermal fatigue in different applications.

\section{Nomenclature}

A

Area of spherical surface indentation in Brinell hardness test. $\left[\mathrm{mm}^{2}\right]$

BHN Brinell hardness number. $\left[\mathrm{Kg} / \mathrm{mm}^{2}\right]$

$\mathrm{d} \quad$ Impression diameter. [mm]

D Ball diameter. [mm]

$\mathrm{N} \quad$ Number of thermal fatigue cycles

F Load of hardness test. $[\mathrm{Kg}]$

$t_{c} \quad$ Cooling time of thermal fatigue cycles. [min]

$t_{h} \quad$ Heating time of thermal fatigue cycles. [min]
$\mathrm{T}_{\mathrm{C}} \quad$ Cooling temperature of thermal fatigue process. $\left[{ }^{\mathrm{O}} \mathrm{C}\right]$ $\mathrm{T}_{h} \quad$ Heating temperature of thermal fatigue process. $\left[{ }^{\mathrm{O}} \mathrm{C}\right]$

\section{Methods Of Analyses}

To evaluate the effect of cyclic heating effect on hardness of steel, the investigation was carried out thus;

- Preparation of the specimens from steel

- Hardness was measured for each specimen after and before cyclic heating operations.

- From the different readings, curves were plotted to know the trends of the property

\section{Equipment Used}

- Laboratory Muffle Furnace

- Hand Polishing Steel Stand

- Hardness Testing machine

\section{Preparation of the Hardness Specimens}

The material used for this study is steel. The sample Fig. 1 preparation was the usual grinding and polishing procedure until a mirrored surface, with no etching, was obtained.

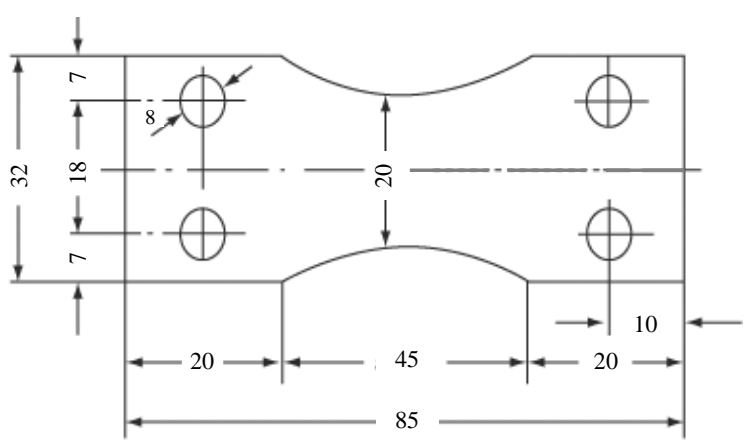

Figure 1. Fatigue sample dimensions in millimeters. Thickness: $1.5 \mathrm{~mm}$.

\section{Brinell Hardness Test}

Brinell hardness is determined by forcing a hard steel or carbide sphere of a specified diameter under a specified load into the surface of a material and measuring the diameter of the indentation left after the test Fig 2.

The Brinell hardness number, or simply the Brinell number, is obtained by dividing the load used, in kilograms, by the actual surface area of the indentation; A, in square millimeters. The result is a pressure measurement, but the units are rarely stated.

The BHN is calculated according to the following formula

$$
B H N=\frac{F}{\frac{\pi}{2} D\left(D-\sqrt{D^{2}-d^{2}}\right)}
$$

Faculty of Engineering, Beni-Suef University

Egypt 
Proc. of The Second Intl. Conf. On Advances in Civil, Structural and Mechanical Engineering - ACSM 2015

Copyright (C) Institute of Research Engineers and Doctors, USA .All rights reserved.

ISBN: 978-1-63248-074-3 doi: 10.15224/ 978-1-63248-074-3-28

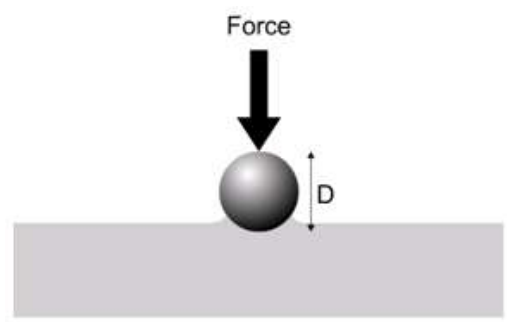

Test Procedure

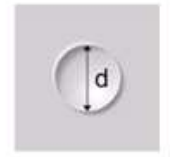

Test Result
Figure 2. Brinell Hardness Test

The ball diameter and applied load are constant and are selected to suit the composition of the metal, its hardness, and the thickness of the rest specimen, Table 1. The diameter of the indentation is measured with a special magnifying glass containing a scale graduated in terms of a millimeter.

TABLE 1. BRINELL TEST CONDITIONS

\begin{tabular}{|c|c|c|c|c|c|c|}
\hline Material & BHN & $\begin{array}{c}\text { Thickness of test } \\
\text { specimen } \\
\text { mm }\end{array}$ & $\begin{array}{c}\text { Ratio of load F } \\
\text { to ball diam. } \\
\text { D }\end{array}$ & $\begin{array}{c}\mathbf{D} \\
\mathbf{m m}\end{array}$ & $\begin{array}{c}\mathbf{F} \\
\mathbf{K g}\end{array}$ & $\begin{array}{c}\text { Time load } \\
\text { application } \\
\text { Sec }\end{array}$ \\
\hline $\begin{array}{c}\text { Steel, cast } \\
\text { iron }\end{array}$ & $\begin{array}{c}\text { Up to } \\
450\end{array}$ & $\begin{array}{c}\text { Over 6 } \\
\text { From 6 to 3 } \\
\text { Less than 3 }\end{array}$ & $\mathrm{F}=30 \mathrm{D}^{2}$ & $\begin{array}{c}10 \\
5\end{array}$ & $\begin{array}{c}3,000 \\
750\end{array}$ & 10 to 30 \\
\hline
\end{tabular}

The chemical composition of the investigated specimen is shown in Table 2.

TABLE 2. THE CHEMICAL COMPOSITION PERCENT.

\begin{tabular}{|c|c|c|c|c|c|}
\hline \multicolumn{7}{|c|}{ Chemical composition\% } \\
\hline $\mathrm{Fe}$ & $\mathrm{C}$ & $\mathrm{SI}$ & $\mathrm{Mn}$ & $\mathrm{Cr}$ & $\mathrm{Cu}$ \\
\hline 99.43 & 0.04 & 0.003 & 0.42 & 0.04 & 0.02 \\
\hline
\end{tabular}

\section{Laboratory Muffle Furnace}

The muffle furnace could be used for heating of test specimen up $1200^{\circ} \mathrm{C}$. Fig. 3 shows the characteristic curves of the muffle furnace.

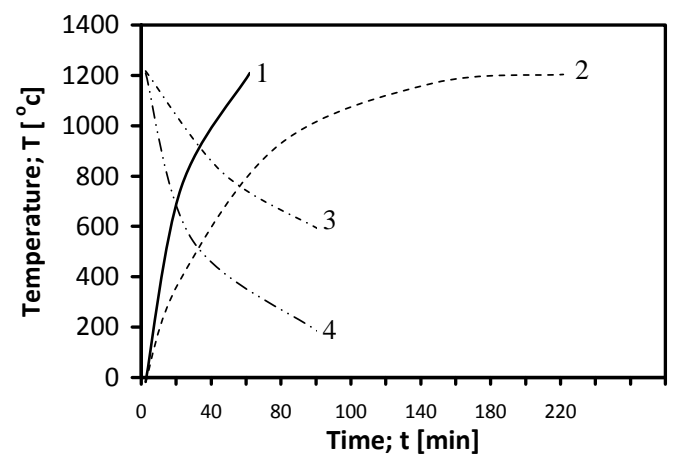

Figure 3. Characteristic curves of the muffle furnace

$$
\begin{aligned}
& 1 \text { Heating - up curve, full load } \\
& 2 \text { Heating - up curve, partial load 50\%. } \\
& 3 \text { Cooling Curve, with door closed. } \\
& 4 \text { Cooling Curve, with door open. }
\end{aligned}
$$

\section{v. Metallographic Test}

The test specimens were firstly polished. A ball of $2.5 \mathrm{~mm}$ diameter is chosen according to Table 1 for the test. The load is applied $31.25 \mathrm{Kg}$ for $30 \mathrm{sec}$.

The hardness values before subjected to thermal fatigue were measured on Brinell hardness tester Table 3 shows the experimental results of hardness test for the specimens of

\begin{tabular}{|c|c|c|c|c|c|c|c|c|}
\hline \multirow{2}{*}{\begin{tabular}{|c|}
$\begin{array}{c}\text { Thermal } \\
\text { fatigue }\end{array}$ \\
\end{tabular}} & \multicolumn{8}{|c|}{ Hardness Test } \\
\hline & \multicolumn{4}{|c|}{$\mathrm{F}=31.25 \mathrm{Kg} \quad \mathrm{D}$} & $2.5 \mathrm{~m}$ & \multicolumn{3}{|c|}{$\mathrm{t}=\mathbf{3 0} \mathrm{sec}$} \\
\hline \multirow{3}{*}{\begin{tabular}{|c|} 
No \\
Thermal \\
fatigue
\end{tabular}} & \multicolumn{4}{|c|}{ First specimen } & \multicolumn{4}{|c|}{ Second specimen } \\
\hline & $\mathrm{d} 1$ & BHN & $\mathrm{d} 2$ & BHN & $\mathrm{d} 1$ & BHN & $\mathrm{d} 2$ & BHN \\
\hline & 0.66 & 89 & 0.66 & 89 & 0.67 & 87 & 0.67 & 87 \\
\hline
\end{tabular}
steel.

TABLE 3. EXPERIMENTAL RESULTS OF HARDNESS TEST OF STEEL WITHOUT THERMAL FATIGUE.

Heating temperatures; $\mathrm{T}_{\mathrm{h}}=100,300$ and $500{ }^{\circ} \mathrm{C}$. Cooling temperatures; $\mathrm{T}_{\mathrm{C}=}$ room temp. $\left(14-28^{\circ} \mathrm{C}\right)$. Heating time $\mathrm{t}_{\mathrm{h}}=10$ min. Cooling time; $t_{C}=15$ min. Number of repeated cycles; $\mathrm{N}=1,3,5,20,30,50,80$ and 100. The values of hardness are registered in Tables 4 to 6 respectively. The relationship between the hardness values versus number of repeated cycles

\begin{tabular}{|c|c|c|c|c|c|c|c|c|c|}
\hline \multirow{2}{*}{\multicolumn{2}{|c|}{$\begin{array}{c}\text { Thermal } \\
\text { fatigue }\end{array}$}} & \multicolumn{8}{|c|}{ Hardness Test } \\
\hline & & \multicolumn{4}{|c|}{$\mathrm{F}=31.25 \mathrm{Kg}$} & $=2.5 \mathrm{~m}$ & \multicolumn{3}{|c|}{$\mathrm{t}=\mathbf{3 0} \mathrm{sec}$} \\
\hline \multirow{2}{*}{$\begin{array}{l}\mathrm{Th} \\
{ }^{\circ} \mathrm{C} \\
\end{array}$} & \multirow{2}{*}{$\begin{array}{c}\mathrm{N} \\
\text { Times }\end{array}$} & \multicolumn{4}{|c|}{ First specimen } & \multicolumn{4}{|c|}{ Second specimen } \\
\hline & & d1 & BHN & $\mathrm{d} 2$ & BHN & $\mathrm{d} 1$ & BHN & $\mathrm{d} 2$ & BHN \\
\hline \multirow{11}{*}{100} & 1 & 0.65 & 92 & 0.65 & 92 & 0.70 & 79 & 0.70 & 79 \\
\hline & 5 & 0.73 & 73 & 0.70 & 79 & 0.70 & 79 & 0.70 & 79 \\
\hline & 10 & 0.70 & 79 & 0.70 & 79 & 0.70 & 79 & 0.68 & 85 \\
\hline & & 0.72 & 75 & 0.72 & 75 & 0.70 & 79 & 0.78 & 64 \\
\hline & 20 & 0.70 & 79 & 0.70 & 79 & 0.70 & 79 & 0.70 & 79 \\
\hline & & 0.79 & 62 & 0.79 & 62 & 0.79 & 62 & 0.77 & 65 \\
\hline & 30 & 0.78 & 64 & 0.79 & 62 & 0.79 & 62 & 0.77 & 65 \\
\hline & 50 & 0.68 & 85 & 0.68 & 85 & 0.68 & 85 & 0.67 & 87 \\
\hline & 70 & 0.67 & 87 & 0.68 & 85 & 0.63 & 63 & 0.65 & 92 \\
\hline & 80 & 0.67 & 87 & 0.68 & 85 & 0.63 & 63 & 0.65 & 92 \\
\hline & 100 & 0.67 & 87 & 0.68 & 85 & 0.63 & 63 & 0.65 & 92 \\
\hline
\end{tabular}
has been plotted in Figs. 4 to 6 .

TABLE 3. EXPERIMENTAL RESULTS OF HARDNESS TEST OF STEEL THERMAL FATIGUE HEATING TEMPERATURE; $\mathrm{T}_{\mathrm{h}}=100^{\circ} \mathrm{C}$.

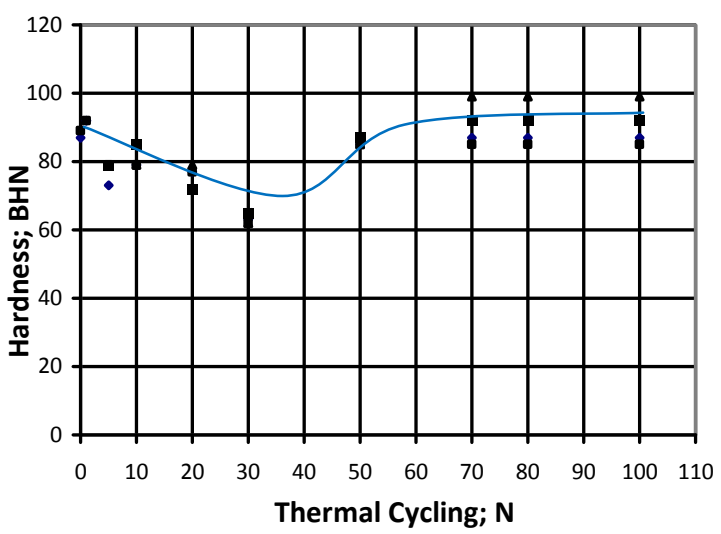

Figure 4. Effect of thermal fatigue on hardness at temperature; $\mathrm{T}_{\mathrm{h}}=100^{\circ} \mathrm{C}$. 
Proc. of The Second Intl. Conf. On Advances in Civil, Structural and Mechanical Engineering - ACSM 2015

Copyright (C) Institute of Research Engineers and Doctors, USA .All rights reserved.

ISBN: 978-1-63248-074-3 doi: 10.15224/ 978-1-63248-074-3-28

TABLE 5. EXPERIMENTAL RESULTS OF HARDNESS TEST OF STEEL THERMAL FATIGUE HEATING TEMPERATURE; $\mathrm{T}_{\mathrm{h}}=300^{\circ} \mathrm{C}$.

\begin{tabular}{|c|c|c|c|c|c|c|c|c|c|}
\hline \multirow{2}{*}{\multicolumn{2}{|c|}{$\begin{array}{l}\text { Thermal } \\
\text { fatigue }\end{array}$}} & \multicolumn{8}{|c|}{ Hardness Test } \\
\hline & & \multirow{2}{*}{\multicolumn{4}{|c|}{$\begin{array}{c}\mathbf{F}=\mathbf{3 1 . 2 5} \mathbf{~ K g} \\
\text { First specimen }\end{array}$}} & $2.5 \mathrm{n}$ & & $t=30 \mathrm{~s}$ & \\
\hline \multirow{2}{*}{$\begin{array}{l}\text { Th } \\
{ }^{\circ} \mathrm{C}\end{array}$} & \multirow{2}{*}{$\begin{array}{c}\mathrm{N} \\
\text { Times }\end{array}$} & & & & & \multicolumn{4}{|c|}{ Second specimen } \\
\hline & & $\mathrm{d} 1$ & BHN & $\mathrm{d} 2$ & BHN & d1 & BHN & $\mathrm{d} 2$ & BHN \\
\hline \multirow{10}{*}{100} & 1 & 0.69 & 82 & 0.67 & 87 & 0.69 & 82 & 0.70 & 79 \\
\hline & 5 & 0.68 & 85 & 0.68 & 85 & 0.69 & 82 & 0.70 & 79 \\
\hline & 10 & 0.67 & 87 & 0.67 & 87 & 0.69 & 82 & 0.71 & 77 \\
\hline & 20 & $\begin{array}{l}0.68 \\
0.65\end{array}$ & $\begin{array}{l}85 \\
92\end{array}$ & $\begin{array}{l}0.68 \\
0.68\end{array}$ & $\begin{array}{l}85 \\
85\end{array}$ & 0.70 & 79 & 0.70 & 79 \\
\hline & 30 & 0.70 & 79 & 0.70 & 79 & 0.74 & 71 & 0.74 & 71 \\
\hline & 30 & 0.70 & 79 & 0.70 & 79 & 0.76 & 67 & 0.70 & 79 \\
\hline & 50 & 0.70 & 79 & 0.72 & 75 & 0.72 & 85 & 0.72 & 75 \\
\hline & 70 & 0.71 & 77 & 0.71 & 77 & 0.72 & 75 & 0.68 & 85 \\
\hline & 80 & 0.71 & 77 & 0.71 & 77 & 0.72 & 75 & 0.68 & 85 \\
\hline & 100 & 0.71 & 77 & 0.71 & 77 & 0.72 & 75 & 0.68 & 85 \\
\hline
\end{tabular}

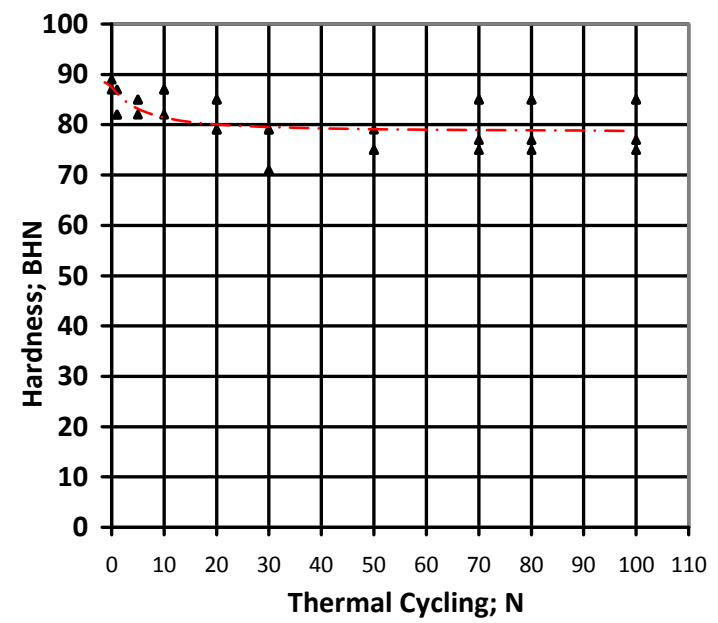

Figure 5. Effect of thermal fatigue on hardness at temperature; $\mathrm{T}_{\mathrm{h}}=300{ }^{\circ} \mathrm{C}$

TABLE 3. EXPERIMENTAL RESULTS OF HARDNESS TEST OF STEEL THERMAL FATIGUE HEATING TEMPERATURE; $\mathrm{T}_{\mathrm{H}}=500^{\circ} \mathrm{C}$.

\begin{tabular}{|c|c|c|c|c|c|c|c|c|c|}
\hline \multirow{2}{*}{\multicolumn{2}{|c|}{$\begin{array}{l}\text { Thermal } \\
\text { fatigue }\end{array}$}} & \multicolumn{8}{|c|}{ Hardness Test } \\
\hline & & \multirow{2}{*}{\multicolumn{4}{|c|}{$\frac{\mathbf{F}=\mathbf{3 1 . 2 5} \mathrm{Kg}}{\text { First specimen }}$}} & \multicolumn{2}{|c|}{$=2.5 \mathrm{~mm}$} & \multicolumn{2}{|c|}{$t=30 \mathrm{sec}$} \\
\hline \multirow{2}{*}{$\begin{array}{l}\text { Th } \\
{ }^{\circ} \mathrm{C}\end{array}$} & \multirow{2}{*}{$\begin{array}{c}\mathrm{N} \\
\text { Times }\end{array}$} & & & & & & econd: & pecime & \\
\hline & & $\mathrm{d} 1 \mathrm{l}$ & BHN & $\mathrm{d} 2$ & BHN & $\mathrm{d} 1$ & BHN & $\mathrm{d} 2$ & $\mathrm{BH}$ \\
\hline \multirow{11}{*}{100} & 1 & 0.73 & & 74 & 71 & & & & \\
\hline & 5 & & & 74 & 7 & 75 & 69 & 5 & 66 \\
\hline & $\mathbf{1 0}$ & & & 0.74 & 7 & 74 & 71 & & 71 \\
\hline & & & & 0.67 & 0 & 0.67 & 87 & & 7 \\
\hline & 20 & 0 & 8 & 0.67 & 87 & 0.69 & 82 & 6 & 82 \\
\hline & & 0 & 7 & 0.70 & 79 & 0.70 & 79 & 0.75 & 69 \\
\hline & 30 & 0. & 7 & 0.70 & 79 & 0.72 & 75 & 0.70 & 79 \\
\hline & 50 & 0.75 & 6 & 0.75 & 69 & 0.75 & 69 & 0.75 & 69 \\
\hline & 70 & 0 & 79 & 0.70 & 79 & 0.73 & 73 & 3 & 73 \\
\hline & 80 & & 7 & 0.70 & 79 & 0.73 & 73 & 0.73 & 73 \\
\hline & 100 & 0.70 & 79 & 0.70 & 79 & 0.73 & 73 & 0.73 & 73 \\
\hline
\end{tabular}

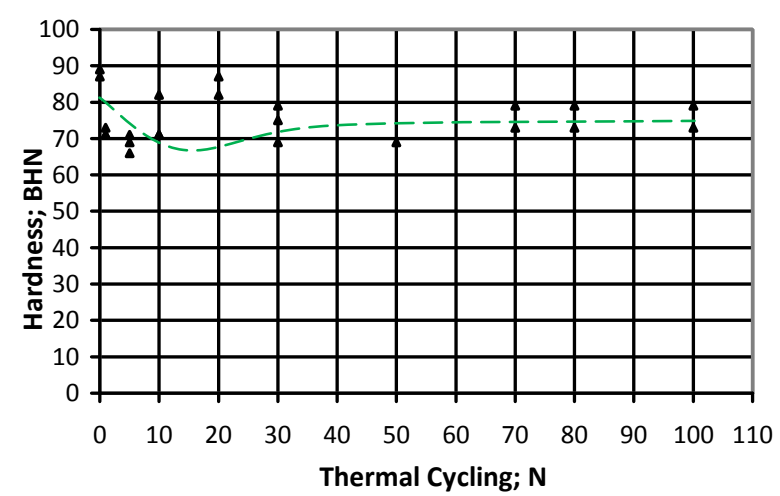

Figure 6. Effect of thermal fatigue on hardness at temperature; $T_{h}=500{ }^{\circ} \mathrm{C}$

\section{Results}

Hardness of steel after thermal fatigue amounted from 87 to $89 \mathrm{HB}$ 2.5/31.25/30. After thermal fatigue, obtained hardness amounted to HB 2.5/31.25/30, at heating temperature; $\mathrm{T}_{\mathrm{h}}=100$ ${ }^{\circ} \mathrm{C}, \mathrm{N}=1$, and was in the range from 92 to $79, \mathrm{~N}=5$ the rang from 73 to $79, \mathrm{~N}=10$ range from 70 to $85, \mathrm{~N}=20$ the rang from 64 to $79, \mathrm{~N}=30$ the rang from 62 to $65, \mathrm{~N}=50$ the rang from 85 to 92 and $\mathrm{N}=70$ to 100 the rang from 87 to 92 Fig. 4 shows the average values of $\mathrm{BH}$ hardness.

In cases of heating temperature 300 and $500{ }^{\circ} \mathrm{C}$ obtained average hardness amounted to $\mathrm{HB} 2.5 / 31.25 / 30$ at different repeated cyclic heating show in Figs. 5 and 6

Comparison of thermal fatigue effect of hardness of steel at different values of heating temperature; $\mathrm{T}_{\mathrm{h}}=100,300$ and 500 show in Fig. 7.

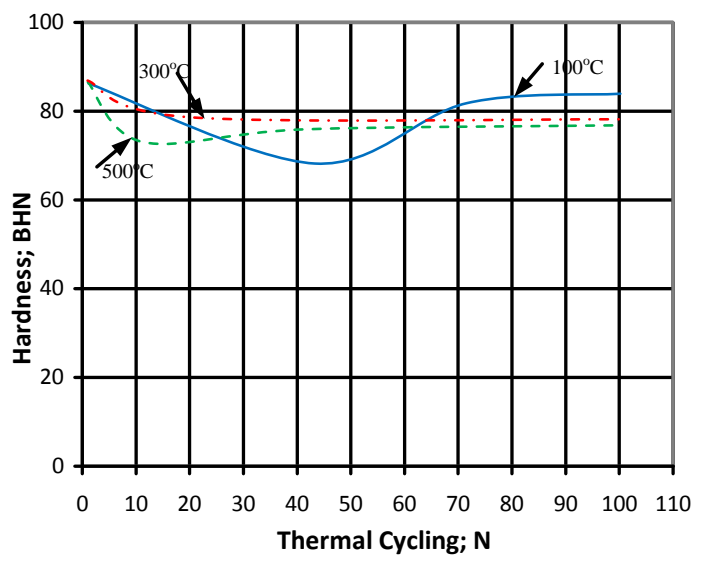

Figure 7. Comparison of thermal fatigue on hardness at different values of heating temperature; $\mathrm{T}_{h}=100,300$ and $500{ }^{\circ} \mathrm{C}$

\section{Conclusion}

The experimental results show that there is a significant effect of cycling thermal treatment on hardness. 
Repeated heating of steel specimens at $100{ }^{\circ} \mathrm{C}$ show a remarked decrease in hardness values by the increase of heating cycles, then it increases again to the initial value, which is about $89 \mathrm{BHN}$, while the minimum value is about 63 $\mathrm{BHN}$ at 30 cycles. By cyclic heating at $300{ }^{\circ} \mathrm{C}$ the hardness decreases slightly only to $77 \mathrm{BHN}$ after 30 cycles, while by heating to $500{ }^{\circ} \mathrm{C}$, the hardness decreases to a value of about 67 BHN after 10 cycles then growth slightly and remains at this value by further heating cycles

\section{Acknowledgements}

The author wish to express their gratitude and deep appreciation to Prof. Dr.-Ing. M. RIZK Faculty of Engineering, Minia University and to the staff of the laboratory for their assistance and help.

\section{References}

[1] Gridnev, V. N. ,et al., Effect of cyclic heat treatment on the phase composition and structure of VT 22 alloy, Izvestiya Akademii Nauk SSSr. Metally, No 3, 1984, 136-141.

[2] Kopp, R., Scheffer, L., Einfluss dus mehrmalingen Erwarmens beim partiellen schmieden von Werkstocken aus, Ti A16 V4, Metall. 37. Jargang. Heft 4. April 1983.
[3] Zabil' Skiy, V. V. and Sarrak, V. I. , Recovery of the properties and the nature strengthening in steels tempered under load, Fiz. metal. Metalloved. Vol. 55, No.2, 1983, 368-373.

[4] Bakhmatov, A. L., Effect of partial cooling and repeated heating in hardening on the structure and properties of nitride parts made of steel $25 \mathrm{khGM}$, Metallovedenie I termicheskaya obrabotka metallov, No. 8, August 1986, 14-16.

[5] Moiseyev, B. A., et at., Effect of thermocycling on the structure and mechanical properties of $35 \mathrm{khN} 2 \mathrm{MF}$ steel, Soviet Materials Science Reviews, 2: 19-22, 1988

[6] Adnan, Calik. Effect of Cooling rate on Hardness and Microstructure of AISI 1020, AISI1040 and AISI 1060 Steels. International Journal of Physics Sciences, 4(9), 2009, $514-518$.

[7] T. Senthilkumar, T. K. Ajiboye Effect of Heat Treatment Processes on the Mechanical Properties of Medium Carbon Steel, Journal of Minerals \& Materials Characterization \& Engineering, 11 (2), 2012, 143-152.

About Author (s):

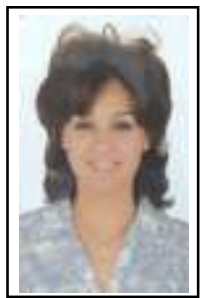

Tahany W. Sadak

Assistant Prof., Department of

Production Engineering and

Design, Faculty of Engineering,

Beni-Suef University

Beni-Suef, Egypt) 